\title{
Uma Experiência com o Uso do GAIA para Inspeção de Acessibilidade do YouTube com foco no autismo
}

\author{
Bruno Henriques de Mendonça \\ Universidade Federal do Ceará \\ Russas - CE - Brasil \\ brunohdem777@gmail.com
}

\author{
Anna Beatriz Marques \\ Universidade Federal do Ceará \\ Russas - CE - Brasil \\ beatriz.marques@ufc.br
}

\begin{abstract}
RESUMO
Usuários com o Transtorno do Espectro Autista (TEA) podem enfrentar barreiras no uso de sistemas interativos, pois apresentam dificuldades em relação à interação social, comunicação, um repertório limitado de interesses e atividades, podendo não compreender ou perceber determinados conteúdos, termos e figuras presentes na interface de sistemas. Diante disto, pesquisas anteriores criaram diretrizes de acessibilidade para pessoas com TEA para auxiliar esses usuários e, mais recentemente, o GAIA: um Guia de recomendações de acessibilidade de interfaces Web com foco em aspectos do Autismo. Pesquisas indicam que o aplicativo de reprodução de vídeos YouTube é muito utilizado por usuários com TEA. A avaliação de acessibilidade foi conduzida por meio de uma inspeção com a participação de oito inspetores. A contribuição deste artigo é o relato da avaliação de acessibilidade do YouTube, apresentado os problemas de acessibilidade identificados.
\end{abstract}

\section{PALAVRAS-CHAVE}

Transtorno do Espectro Autista, Acessibilidade, Inspeção

\section{Introdução}

Os usuários com o Transtorno do Espectro Autista (TEA) apresentam diferentes níveis de habilidade comparados com pessoas que não possuem TEA pois, geralmente apresentam dificuldades em relação à interação social, comunicação, bem como um repertório limitado de interesses e atividades [1]. Devido às dificuldades para entender expressões, os usuários autistas podem não compreender ou perceber determinados conteúdos, termos e figuras presentes na interface de aplicações.

Por isso surgiram pesquisas que propõem diretrizes para a construção de interfaces acessíveis aos autistas como as diretrizes do Guia de Acessibilidade de Interface web focados em aspectos do Autismo (GAIA) [1].

Permission to reproduce or distribute, in whole or in part, material extracted from this work, verbatim, adapted or remixed, as well as the creation or production from the content of such work, is granted without fee for non-commercial use, provided that the original work is properly credited.

IHC 2019 - TRILHA PÔSTERES E DEMONSTRAÇÕES, Outubro 21-25, 2019, Vitória, Brasil. In Anais Estendidos do XVIII Simpósio Brasileiro sobre Fatores Humanos em Sistemas Computacionais. Porto Alegre: SBC.

(C) 2019 by the author(s), in accordance with the terms of the Creative Commons Attribution-NonCommercial 4.0 International Public License (CC BY-NC 4.0).
O GAIA foi adotado em uma inspeção de acessibilidade executada em [1] no aplicativo o dado da Guga, que é um jogo voltado para crianças com TEA que visa trabalhar habilidades como atenção e compreensão de expressões faciais. O GAIA também foi adotado no redesign de aplicativos móveis direcionados a pessoas com TEA [3]

Ferreira et al. [2] relatam um survey sobre o uso de tecnologias por pessoas com TEA, que obteve como respondentes 52 mães, pais ou responsáveis de crianças com TEA com faixa etária de 2 a 14 anos de todas as regiões do Brasil. Essa pesquisa indicou que o aplicativo mais utilizado por essas crianças é o YouTube. O aplicativo YouTube contém um número elevado de usuários, com mais de 1 bilhão de usuários [4].

Com base neste resultado, decidiu-se realizar a inspeção de acessibilidade do aplicativo YouTube orientado pelas diretrizes do GAIA.

\section{Metodologia}

A inspeção executada nessa pesquisa se baseou na inspeção realizada em [1]. Os participantes escolhidos para avaliar a aplicação web foram os alunos de um projeto de pesquisa e extensão denominado ProDTeA (Projeto e Desenvolvimento de Tecnologias Acessíveis) da Universidade Federal do Ceará (Campus Russas). Todos os alunos possuíam conhecimento sobre o TEA. Dois participantes executavam pesquisas há pelo menos um ano antes da realização dessa inspeção, três participantes realizavam pesquisas há um semestre e três participantes executavam pesquisa há um mês. Seis participantes eram do curso de Engenharia de Software e dois participantes eram do curso de Ciência da Computação. Os passos adotados na inspeção foram os seguintes:

1. Envio das diretrizes para os participantes: Foram enviadas por e-mail as diretrizes do GAIA para os participantes da inspeção uma semana antes da inspeção de acessibilidade.

2. Inspeção de acessibilidade do aplicativo YouTube: A inspeção foi executada por 8 participantes que foram denominados inspetores em um laboratório de informática em computadores de mesa com tempo limite de duas horas. A inspeção foi executada individualmente. As tarefas definidas para os inspetores avaliarem foram: (i) acessar o sistema na página inicial, (ii) executar a busca de vídeos nas páginas de busca de vídeos e (iii) visualizar os resultados da busca e (iv) reproduzir um vídeo. Durante a inspeção, os inspetores consultavam o material 
de apoio sobre as diretrizes do GAIA e registravam em uma planilha os problemas de acessibilidade identificados.

3. Verificação de falso-positivos: Os autores desse trabalho se reuniram para discutir se os problemas encontrados eram reais ou falso-positivos. Os defeitos falso-positivos foram removidos do registro de defeitos.

\section{Problemas de acessibilidade identificados}

Essa seção apresentará os problemas encontrados por página do YouTube inspecionada. Em todas as páginas inspecionadas, foram identificados os seguintes problemas de acessibilidade: (1) Não existe prevenção de erro por sensibilidade ao toque dos botões (diretriz 10.1 do GAIA); (2) Não é permitido a alteração da fonte do texto no aplicativo (diretriz 2.1); (3) Alguns botões não aparentam ser clicáveis (diretriz 7.1).

$\mathrm{Na}$ página inicial (lado superior da Figura 1), foram identificados os seguintes problemas de acessibilidade: (1) Não é permitido customizar a quantidade de elementos da tela (diretriz 2.3); (2) Alguns ícones contidos nos botões não representam a função dos botões (diretriz 1.4); (3) Alguns ícones têm baixo contraste com a tela (diretriz 1.1); (4) Existem botões muito próximos e botões com área de clique pequena (diretriz 7.2); (5) Existem ícones iguais com textos diferentes (diretriz 4.1); (6) Não existe uma opção para customizar o layout da página (diretriz 2.3); (7) Existem muitas sugestões de vídeos para assistir dificultando o uso (diretriz 3.2).

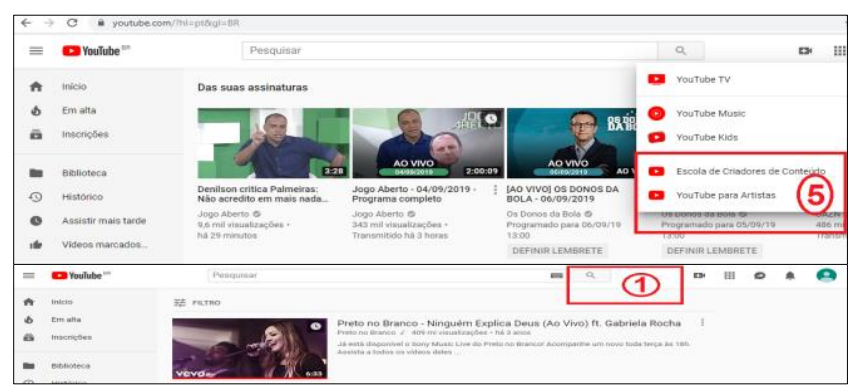

Figura 1: Página inicial e página de busca do YouTube

Na página de busca (lado inferior da Figura 1), os seguintes problemas de acessibilidade foram identificados: (1) O botão de pesquisa não tem um texto associado (diretriz 1.1); (2) Em todas as figuras da página de busca não existe uma opção para customizar o layout da página (diretriz 3.4); (3) O campo de busca está com baixo contraste (diretriz 1.1).

Na página de resultados (lado superior da Figura 2), é possível destacar os seguintes problemas: (1) Não é permitido customizar a quantidade de elementos da tela; (2) Os ícones não tem um texto associado (diretriz 10.1); (3) O botão de pesquisa não tem um texto associado (diretriz 1.1); (4) A opção de vídeos a serem reproduzidos são representados apenas como imagens (diretriz 10.1); (6) A descrição dos vídeos estão na mesma formação dos dados do vídeo (diretriz 1.1).

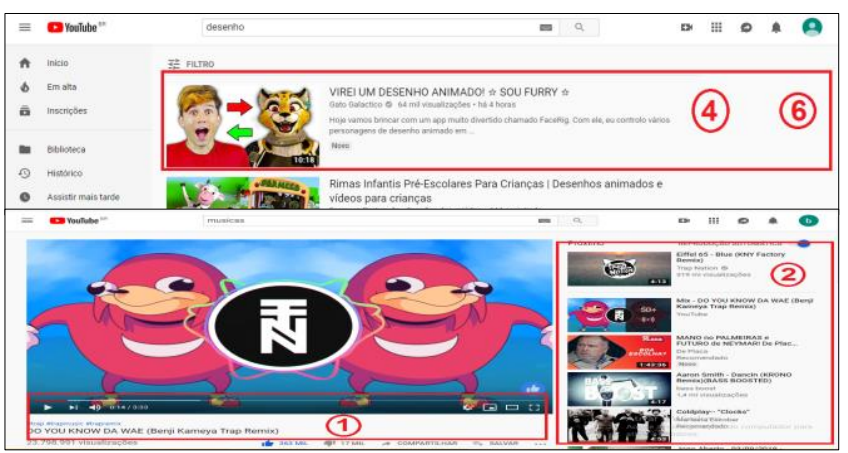

Figura 2: Página de resultados e de reprodução de vídeo do YouTube

Na página de reprodução de vídeo (lado inferior da Figura 2) foram identificados os seguintes defeitos: (1) As funções de reprodução do vídeo como reproduzir, pausar e volume não contém representação nominal (diretriz 4.2); (2) Não tem como suprimir vídeos da lateral da tela tirando o foco do usuário (diretriz 4.3); (3) Não tem padrões de cores entre os botões para fazer um comentário e cancelar comentário (diretriz 1.1).

\section{Considerações Finais e Trabalhos Futuros}

O objetivo dessa pesquisa foi avaliar a acessibilidade do YouTube, uma aplicação amplamente utilizada por crianças com TEA, de acordo com pesquisas anteriores. Alguns problemas de acessibilidade foram identificados e apresentados neste artigo. Espera-se, com este relato, motivar a comunidade acadêmica a executar outras pesquisas sobre acessibilidade em aplicações existentes, inclusive aplicações direcionadas para pessoas autistas.

\section{REFERENNCIAS}

[1] Talita C.G. Britto e Ednaldo B. Pizzolato. 2018. GAIA: uma proposta de um guia de ecomendações de acessibilidade de interfaces Web com foco em aspectos do Autismo. Revista Brasileira de Informática na Educação (RBIE) 26, 2: 102 -123.

[2] Verilene D. Ferreira, Tamires A.Sousa, Marília S. Mendes e Anna B. S. Marques. 2018. Investigando o uso de tecnologias de software por pessoas com Transtorno do Espectro Autista. In: Anais Estendidos do XVII Simpósio Brasileiro sobre Fatores Humanos em Sistemas Computacionais. Porto Alegre: Sociedade Brasileira de Computação, oct. 2018. DOI https://doi.org/10.5753/ihc.2018.4193

[3] Bruno Mendonça, Carlos J.S. Lopes, Marília S. Mendes e Anna B. S. Marques. 2018. Redesign de aplicativos para pessoas com Transtorno do Espectro Autista orientado pelas diretrizes do GAIA. In: Anais Estendidos do XVII Simpósio Brasileiro sobre Fatores Humanos em Sistemas Computacionais. Porto Alegre: Sociedade Brasileira de Computação, oct. 2018. DOI: https://doi.org/10.5753/ihc.2018.4198.

.[3] YouTube para a imprensa. 2019. Disponível em: <https://www.youtube.com/intl/pt-BR/yt/about/press/ >. Acesso em: 13 agosto. 2019. 